
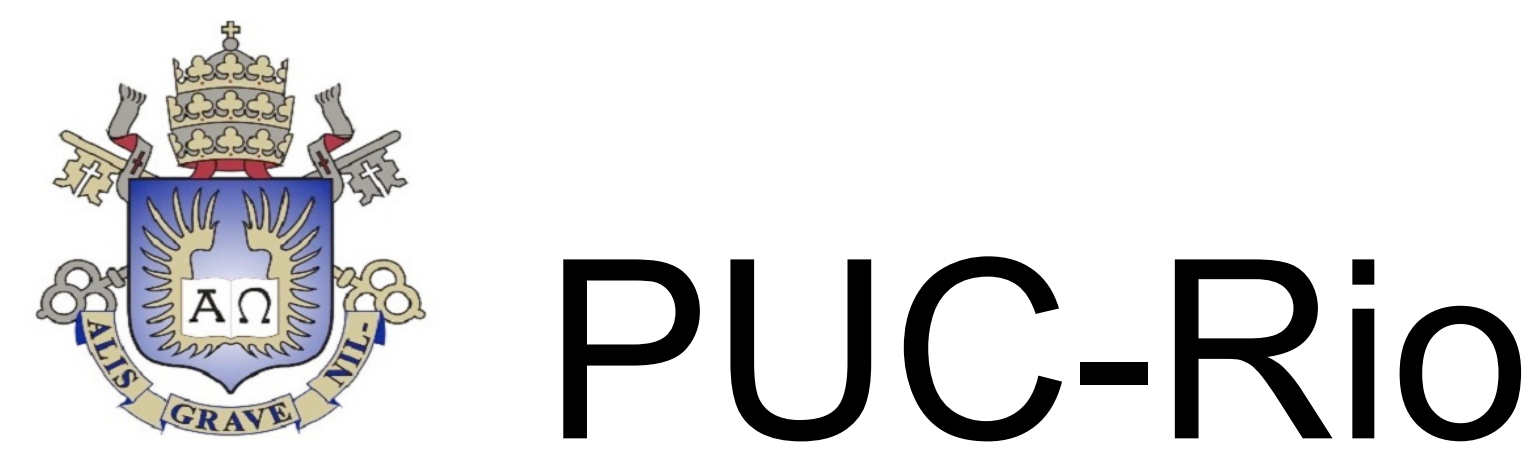

DEPARTAMENTO DE PSICOLOGIA

\title{
DA PROPOSTA A UMA PRÁXIS PSICOTERAPÊUTICA TRIDIMENSIONAL
}

por

FELIPE XAVIER DE MORAES

ORIENTADOR: ÁLVARO DE PINHEIRO GOUVÊA

2018.1

PONTIFÍCIA UNIVERSIDADE CATÓLICA DO RIO DE JANEIRO RUA MARQUÊS DE SÃO VICENTE, 225 - GÁVEA - CEP 22451-000 RIO DE JANEIRO - BRASIL 


\section{DA PROPOSTA A UMA PRÁXIS PSICOTERAPÊUTICA TRIDIMENSIONAL}

por

FELIPE XAVIER DE MORAES

TCC Apresentado ao Depto. de Psicologia da Pontifícia Universidade Católica do Rio de Janeiro (PUC-Rio) para a obtenção do Título de Psicólogo.

Orientador: Prof. Álvaro de Pinheiro Gouvêa 
SUMÁRIO

INTRODUÇÃO

1 - SOBRE A INSERÇÃO DO OBJETO MATERIAL EM PSICOTERAPIA .........................................

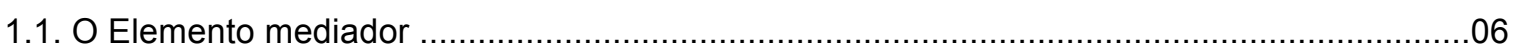

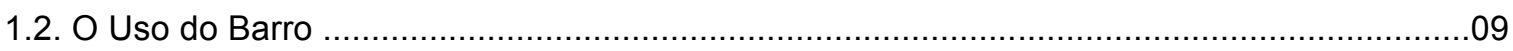

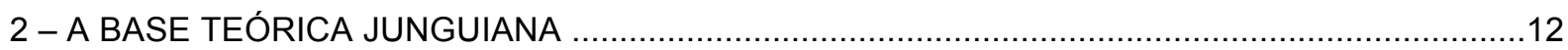

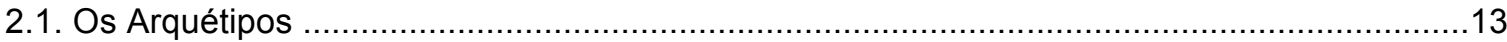

2.2. Uma possível Aplicação do Modelo Arquetípico.....................................................................15

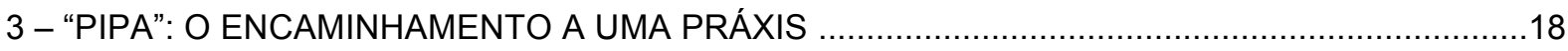

3.1. Teorizando a Práxis e Buscando sua Fundamentação ........................................................18

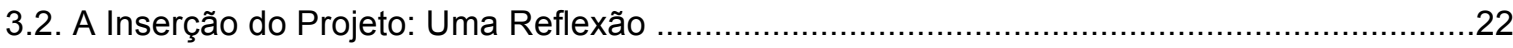

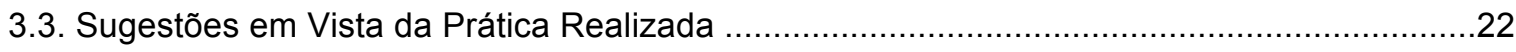

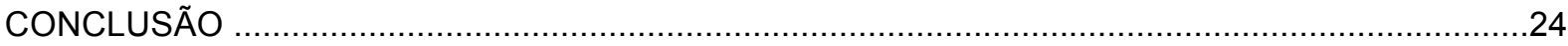

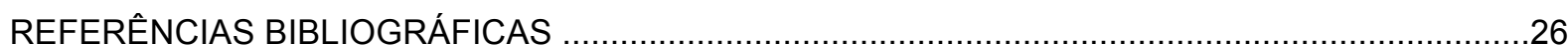

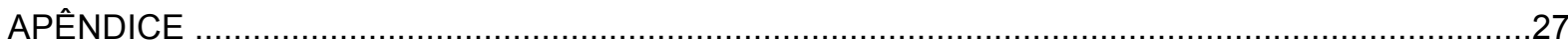




\title{
RESUMO
}

A inspiração para este trabalho decorreu da experiência de estágio orientada pelo Professor Álvaro de Pinheiro Gouvêa quando do oferecimento da disciplina "Estágio Básico II", na PUC-Rio, no decorrer do Primeiro Semestre de 2015. O campo de atuação foi a comunidade adjacente à Universidade, denominada Vila Parque, tendo a presença de uma aluna monitora conduzindo as atividades neste meio.

O ponto de partida foi a inserção no projeto "PIPA" (Produções do Imaginário e Psicologia Aplicada). Perscrutamos sua base teórica, de cunho psicanalítico junguiano, por meio da qual discorremos acerca das significações da introdução do objeto material em psicoterapia e seus desdobramentos no que concerne à denominada interpretação de "objeu", que abre o trabalho a uma perspectiva lúdica, criativa, instaurando o brincar psicanalítico, para que seja possível tratar com leveza e descontração as próprias neuroses.

Considerando a índole social do projeto, pontuamos a importância de uma iniciativa desta natureza para a formação do futuro profissional da Psicologia e para a própria Psicologia, por favorecer a penetração tanto do psicólogo quanto da Ciência Psicológica em meios nos quais não se fazem presentes com tanta regularidade. Por fim, apresentamos sugestões do ponto de vista do empreendedorismo no intuito de alargar as possibilidades de utilização do que aqui se propõe.

Palavras-chave: objeto material; inconsciente pessoal; inconsciente coletivo; arquétipo; objeu.

\begin{abstract}
The inspiration for this research came from the internship experience guided by Professor Álvaro de Pinheiro Gouvêa when the course "Basic Internship II" was offered, at PUC-Rio, during the first semester of 2015. The field of action has been the community adjacent to the University, called Vila Parque, with the assistance of a student monitor conducting the activities.

The starting point has been the insertion in the "PIPA" project (Productions of the Imaginary and Applied Psychology). We have scrutinized its theoretical basis, of Jungian psychoanalytic nature, through which we have discussed the meanings of the introduction of the material object in psychotherapy and its developments in what concerns the so-called "objeu" interpretation. Hence, that opens works to a ludic and creative perspective, establishing psychoanalytic playing, for this reason it is possible to treat one's own neuroses with lightness and relaxation.

Considering the social concerns of the project, we point out the importance of an initiative of this nature for the formation of future Psychology professionals and for Psychology itself, by favoring the penetration of both the psychologist and the Psychological Science in environments where they are not so regularly present. Finally, we present suggestions from the point of view of entrepreneurship in order to broaden the possibilities of use of what is proposed here.
\end{abstract}

Keywords: material object; personal unconscious; collective unconscious; archetype; objeu. 


\section{INTRODUÇÃO}

No presente trabalho, unimos análises teóricas desenvolvidas em sala de aula, junto ao professor Álvaro de Pinheiro Gouvêa, à prática de estágio que nos foi proporcionada, e que será pormenorizadamente tratada mais adiante, visando uma reflexão a contribuir tanto na formação pessoal de um futuro profissional da Psicologia, quanto no desenvolvimento teórico e prático das atividades nas quais estivemos envolvidos.

A base teórica é psicanalítica de cunho junguiano, trazendo a perspectiva da inserção do objeto concreto nas sessões de análise. No primeiro capítulo trataremos do significado e desdobramento da introdução de tal elemento no jogo psicoterápico, em vista da eleição do barro para este fim.

Já no segundo capítulo, vislumbraremos o quão esta proposta vai ao encontro do que C. G. Jung qualificaria como uma experiência arquetípica, oferecendo para isso, primeiramente, os contornos do conceito de "arquétipo", subsumido do próprio psiquiatra e psicoterapeuta suíço, para, nesta esteira, insinuarmos uma possível aplicação deste modelo no que tange a uma práxis terapêutica.

Desta incursão resulta o "PIPA" (Produções do Imaginário e Psicologia Aplicada), do qual trataremos no terceiro e último capítulo. A aventura de cunho experiencial, peculiar a este trabalho, enriquece a dinâmica desenvolvida na ação terapêutica. Lançaremos mão dela como pano de fundo para tratarmos de dois pontos fundamentais.

O primeiro ponto é o da significação mais profunda da inserção do objeto material na terapia, quando da abertura à noção de objeu, decorrente da necessidade de tomar o dito objeto, na metodologia proposta, no seu equilíbrio dinâmico entre o captado empiricamente e o aspecto ideal em que está engendrado. Viabiliza-se, neste ensejo, pensar a relação analítica em uma perspectiva tridimensional, no envolvimento estabelecido entre analista, analisando e objeto externo, este que por sua vez torna-se suporte de materialização das emoções e elemento por meio do qual se passa a ter o controle sobre as neuroses, tendo-as nas mãos.

O outro ponto é o da experiência em campo, conforme veremos. Nota-se o favorecimento para a formação do futuro profissional da Psicologia, sobretudo enquanto cidadão, considerando a atuação em comunidades menos providas socialmente; também a Psicologia sai favorecida, na medida em que encontra entrada em ambientes nos quais não penetraria com tanta facilidade. No mais, apresentaremos sugestões, inclusive do ponto de vista do empreendedorismo, para o tipo de trabalho aqui exposto, alargando - ao nosso modo de ver - as possibilidades de utilização do método. 


\section{CAPÍTULO 1}

\section{SOBRE A INSERÇÃO DO OBJETO MATERIAL EM PSICOTERAPIA}

A inserção do objeto material em psicoterapia nos remete a uma perspectiva dialética, no entendimento do Professor Álvaro de Pinheiro Gouvêa (GOUVÊA, 1989), em que o dito objeto e o ser humano se implicam mutuamente num processo criativo que o autor chama de "gratificante". Pensar esta última palavra nos termos aqui propostos, remeter-nos-ia a uma dinâmica de prazer, de satisfação, diríamos até de realização do ser.

Dar-se-ia um encontro de possibilidades entre a natureza inconsciente do ser humano e a inconsciência da própria matéria, do objeto material, num processo de mútua implicação, no sentido de que um teria muito a "dizer" do outro. Diante da matéria informe, dentro do jogo psicoterápico, de imediato, há um remetimento a algo de nós que não sabemos bem o que é, contudo temos a impressão de parecer remontar às nossas origens, e não só isso, também àquilo que somos.

Já fazendo referência à escolha do tipo de objeto, o barro, sobre o qual mais adiante discorreremos de maneira pormenorizada, temos no universo bíblico um subsídio importante para clarificar as evidências pontuadas acima. Sobre o remetimento às origens, não podemos perder de vista que em um dos relatos da criação ${ }^{1}$, dentro da abordagem escriturística, o homem foi feito do barro. Não que esta fonte em si seja a última palavra no assunto e portadora do argumento de autoridade responsável por fechar a questão. Nós a tomamos para poder ilustrar, na perspectiva Junguiana, a relevância da força simbólica desta imagem primordial no inconsciente coletivo de uma determinada cultura, que faz emergir a energia necessária ao empreendimento da busca filosoficamente legítima quanto às nossas origens. Nesta esteira impõem-se indagações acerca de onde viemos e, consequentemente, para onde vamos.

É nesta acepção que o ser humano se reporta às suas origens. Simbolicamente, a manipulação do barro permite o contato com o nosso substrato, a matéria prima na qual de alguma maneira nos encontramos ainda informes, em potência. O potencial com o qual nos deparamos acaba por se traduzir em termos de possibilidades e possibilidades de ser, quando se chega a esboçar aquilo que efetivamente somos.

\footnotetext{
${ }^{1}$ A Bíblia contém dois relatos da criação no início do livro do Gênesis, o pertencente à fonte Sacerdotal (Gn1,1$2,4 \mathrm{a})$ e o pertencente à fonte Javista $(\mathrm{Gn} 2,4 \mathrm{~b}-25)$, sendo esta a que nos referimos. "A tradição que mencionamos por primeiro, designada pela sigla $\mathrm{P}$, deve-se aos sacerdotes do Templo de Jerusalém, caracterizada por uma abordagem legalista e litúrgica que a influência. Já a fonte Javista, designada pela sigla $\mathrm{J}$, assim chamada porque utiliza o nome divino Iahweh desde a narração da criação, teve origem em Judá e talvez tenha sido escrita, quanto ao essencial, no reinado de Salomão. Tem um estilo vivo e colorido; numa forma cheia de imagens e com um modo de narrar realmente magistral, ela dá uma resposta profunda aos graves problemas que se apresentam a todo homem.” - BÍBLIA DE JERUSALÉM, Introdução ao Pentateuco, São Paulo: 2003, pp.23-24.
} 


\subsection{O ELEMENTO MEDIADOR}

O tópico do qual nos ocuparemos, de antemão nos impõe pensar se o mais correto seria discorrer sobre "o elemento mediador" ou sobre "elementos mediadores". A dúvida decorre do entendimento acerca do próprio papel do terapeuta dentro do processo psicoterápico. A este caberia a tarefa de mediar forças inconscientes que emergem na relação estabelecida no interior do setting (GOUVÊA, 1989), cuja organização se faz necessária para que o trabalho obtenha fluidez.

Acontece, por sua vez, de ser um tanto quanto óbvia, embora passível de inúmeras problematizações, a natureza da mediação a qual nos referimos acima. Sai do círculo da obviedade cogitar um elemento outro que, neste meio, seja capaz de pressupor a ação dos atores habituais (o terapeuta, o cliente) e ainda aglutiná-los em si. Referimo-nos à inserção do objeto material no meio em questão, tomado não da forma grosseira e esvaziada segundo a ótica do senso comum, mas sim numa visada simbólica, cujo empreendimento sobre o referido ente faz pressentir uma atuação, em última instância, sobre aqueles mesmos que o manuseiam. Constitui-se, assim, uma forma menos arriscada de manipular-se, experimentar-se, construir-se e reconstruir-se.

Estamos nos referindo, nestes termos, a uma prática analítica entendida aos moldes de um processo dialético, em que se compõe a trilogia "analista-objeto material-analisando". É de grande valia ressaltar que o modelo de dialética em questão não é o clássico hegeliano, mas sim o que se identifica com o pensamento de Octave Hamelin, cujo trabalho inspirou Gaston Bachelard. Desta fonte bebe o professor Álvaro Gouvêa para nos inspirar a lançar mão de um "método sintético" no qual tese e antítese ao invés de estabelecerem relação de oposição entre si, antes, ambos se complementam, e sem contradição (GOUVÊA, 1989).

O professor Álvaro explicita a ideia acima com base na consideração feita por Bachelard (GOUVÊA, 1989). Nesta, chega-se bem perto do pretendido ao supor ter como garantia para se chegar a uma mesma opinião acerca de algo a certeza de ter havido de início discordância. A verdade, que não é filha da simpatia, mas sim da discussão, caso queiramos ilustrar, nasce da tentativa de entendimento entre dois homens que, para se entenderem efetivamente, verificam primeiro a necessidade de se contradizerem (BACHELARD, 1984).

O pensar dialético no qual nos inserimos jamais deixará de contrapor os opostos, até porque se assim fosse seria inviável o remetimento ao método em questão. Todavia, a especificidade aqui decorre do nexo de causalidade que conseguimos observar na relação estabelecida entre os entes relacionados. Dir-se-ia um contexto de mútua implicação que nos permitiria falar em reciprocidade causal, que, no entendimento de Bachelard, colocada a problemática no nível do encontro entre sujeito e objeto, faria emergir, não obstante as diferenças de ambos, um estado de correlação. Por conhecimento, nos termos precedentes, entender-se-ia a síntese entre os dois (GOUVÊA, 1989).

Quando em síntese, inter-relacionados, sujeito e objeto formariam uma única estrutura, impensável fora dessa relação. Um se amoldaria ao outro. O desdobramento disso vai longe, e permitiria cogitar uma solução para o clássico problema existente no universo tanto da Filosofia 
quanto da Psicologia, da comunicação entre mente e corpo / corpo e mente. Sob o influxo da dialética da qual lançamos mão torna-se possível saber do que se trata ao nos referirmos a um espírito encarnado, tanto quanto a um corpo espiritualizado. Nada disso soará estranho, nesta perspectiva.

Rompe-se, pela medida proposta, com modelos de psicoterapias marcadamente "monistas", no sentido de considerar a realidade constituída por um princípio único, tudo reduzindo a uma empobrecedora unidade, à revelia da multiplicidade de combinações possíveis do pensamento humano. Formas racionalizadas, muito retas e iguais na tomada das questões constituem grande perigo para os implicados no jogo psicoterápico. Corre-se o risco de cair em reducionismos, abrindo mão de aprender o pensamento científico contemporâneo em sua dialética, com toda carga sintética essencial capaz de dar conta da "razão-experiência" em sua dinâmica energética.

Irrompe certo modelo de abordagem cujo intuito seria o de pressupor os entes envolvidos na sua ação considerando-os na integralidade que Ihes é própria. $O$ todo de cada um está integrado por sua vez a um todo maior, numa holística peculiar ao mecanismo de funcionamento da própria natureza em vista da homeostase garantidora da vida. Não existe, no plano da biosfera, sabemos bem, nada que esteja fora da relação, como que numa sinfonia, na qual todos os sons estão implicados e compondo em última instância uma música; ou como um grande mosaico, no qual cada fragmento ajuda a compor a totalidade da obra.

Bem paradoxal se mostra certa maneira de fazer ciência, que embora imbuída dos princípios de investigação do mundo natural, não vem a considerar o aspecto relacional dos objetos sobre os quais se debruça. Aqui se torna impensável nos referirmos a mútua implicação, reciprocidade causal ou a algo do gênero, tão importantes no trabalho da construção das identidades. Há de convir estar posto em dúvida qualquer método que ouse afirmar o que as coisas são, sem inferir exatamente sobre a maneira como se dão: na síntese relacional. No mais, estaríamos compreendendo apenas os processos, os modos de funcionamento, não o ser.

Nada pode parecer tão claro e distinto como antes. Ou será o critério de clareza e distinção convencionado pelo racionalismo mecanicista o instrumento de má fé que prescinde da complexidade das relações e simplifica a forma de abordar? Desde que se tome de forma absoluta esta maneira de conhecer diríamos que sim, existiria má-fé nisso. A partir do momento, contudo, que se reconhece a incapacidade deste princípio em dar conta da multiplicidade das combinações resultantes das mútuas implicações entre os entes em relação, restringe-se o método supracitado, conforme a colocação feita no parágrafo acima, nada mais nada menos ao entendimento dos processos, dos modos de funcionamento.

Nosso objetivo não é desqualificar o tratamento da realidade num nível assim, até porque existe lugar para isso. Pretendemos trazer ao jogo psicoterápico um olhar diante do qual não escape a riqueza do que fica do contato estabelecido entre os entes. Resulta uma síntese em um e em outro, de um e de outro, remanescente da fluidez dialética decorrida do encontro. O encaminhamento dado até o momento faz supor a profundidade das significações passíveis de serem desdobradas da inserção do objeto material em psicoterapia: 


\begin{abstract}
O constante contato corpo-a-corpo com o objeto instaura uma nova dimensão ao nível da consciência. O objeto serve de continente a projeções humanas e o homem, tendo a matéria como espelho, se vê refletido no mais profundo do seu ser. Do encontro do homem com o "objeto material" nasce um momento novo, mágico. O homem se alarga em sua consciência e o objeto se torna um novo objeto ao conter a energia criadora que evidencia o momento de síntese acontecido na dialética "sujeito-objeto". O objeto muda mas não perde a sua concretude de objeto, não se mascara, embora mude de forma. Essa constância objetal interfere no que há de material no imaginário do homem e, na dialética, o ser do homem e do objeto segue seu curso criador. $O$ objeto concreto se faz necessário sempre para que o mundo externo não se transforme numa metáfora constante. (GOUVÊA, 1989, p.28).
\end{abstract}

No contexto a que nos referimos, o objeto cumpriria experimentalmente o papel de ponto de toque da linguagem metafórica e abstrata com o campo da concretude. Naturalmente, no encaminhamento do trabalho psicoterápico, haveria uma redução do gasto energético e consequentemente de tempo que se levaria até chegar a isso. Realiza-se a constituição de um atalho por meio do qual, à luz de Nise da Silveira (2015), as imagens inexplicáveis e confusas do inconsciente encontrariam possíveis formas de expressão em vista de facilitar o desembaraço, mesmo que isso, numa acepção Junguiana (JUNG, 2013), implicasse no afloramento de impressões visuais da fantasia.

A ação terapêutica, aberta a uma abordagem desta natureza, sob o influxo do princípio dialético por que se orienta, precisa dar margem para que seja dito o indizível acerca do objeto material. A esse ponto é chegado após ser esgotado o que era possível de ser dito, quando dali por diante tem início a especulação sobre o não dito. Decorre desse jeito a passagem do não ser ao ser, mais propriamente o vir-a-ser, a tomada de consciência, a clarificação, o desembaraço.

No que diz respeito ao objeto, quanto mais primitivo ele for, melhor será. A impressão de maior liberdade diante do incondicionado parece contundente, cria a atmosfera propícia a certo descompromisso, favorece o lúdico, a brincadeira, a arte, distrai as defesas do inconsciente a fim de fazer em algum momento o sujeito ser surpreendido falando de si quando tinha por certo estar referindo-se ao objeto. Ademais, qual seria a importância do princípio dialético pelo qual enveredamos senão essa? Nisso ele cumpre o seu papel e dá mostras de relevância no interior do projeto do qual pretendemos dar cabo.

\title{
1.2 O USO DO BARRO
}

Por demais desafiadora se mostra a tarefa de escolher o objeto mais oportuno para o uso no espaço do consultório. Observa-se que no nível da análise individual existe a necessidade do terapeuta estar muito bem inteirado do que se desdobra no imaginário do analisando quando do uso 
de tal objeto, além de não poder perder de vista as mais variadas implicações da ordem do imaginário subsumidas do encontro com este elemento. $O$ exame do que daí decorre precisa ser confrontado, na medida do possível, com o processo em sua totalidade e também com os resultados concretos trazidos à luz na forma de transformações no âmbito das vivências tanto do analisando quanto do analista.

As exigências que cercam o terapeuta vêm com o objetivo de minimizar o impacto da contratransferência em seu caso. Supomos repercutir no analista a força que impactou o analisando quando do encontro com o objeto material. Se porventura o profissional não conseguir elaborar o que Ihe sobreveio, corre o risco de se perder arrastado pela mesma potência, juntamente com aquele que recorreu ao seu trabalho.

No caso do analista, saber o porquê de ter feito a escolha por determinado objeto material e ao mesmo tempo estar ciente dos possíveis acometimentos que o mesmo pode propiciar tanto a si quanto ao analisando, de sobremaneira o ajudará a determinar as suas próprias projeções. Fica com isso o registro da existência de um projeto, de um fio condutor na execução do trabalho, a certeza de que o terapeuta não está à mercê, mas sim sabedor de onde pretende chegar.

Antes do prosseguimento vale ressaltar que embora tenhamos discorrido com certa naturalidade com relação à inserção do objeto material nas sessões de análise, é possível que não haja uma intervenção assim. Fará a diferença a receptividade do analisando, se aceitará ou não a entrada de um terceiro neste processo. Aí surge a necessidade de outro esclarecimento: da compreensão do objeto, segundo a perspectiva do Prof. Álvaro Gouvêa (1989), do ponto de vista não de um simples intermediário, ou de um elemento relacional apenas. Ele possui conotações bem específicas no enquadre no qual pretendemos colocá-lo, porque tem um peso tão importante quanto o do analista e do analisando.

Isto posto, há de convir que sejam muitos os objetos passíveis de serem transformados no que denominamos "Objeto Material", no objeto que à luz do consenso estabelecido entre analista e analisando pode ter relevância no cerne da dinâmica analítica. Facilita pensar no que seja bem definido, mas que ao mesmo tempo possa valer como símbolo da ausência, capaz de fazer o imaginário aflorar.

Ao analista caberia trabalhar o imaginário do analisando perscrutando o ausente do seu psiquismo, transformado em realidade capaz de ser percebida instantaneamente. A captação da ausência implicaria num desejo inconsciente por um objeto que possa preencher o vazio, por conseguinte propiciando a aproximação com o real. Surge o desafio, especialmente da parte do analista, de encontrar na natureza o objeto material por meio do qual se reconstruirá a unidade perdida na origem, com o que se mantém acesa a busca por completude. E se faz necessário que seja algo cujo manuseio favoreça a compreensão de que, em última instância, o que se está a manusear seja a si mesmo, no reconhecimento das próprias transformações nas transformações pelas quais passa o objeto. 
Essas características que reconheço no objeto material fazem com que o objeto usado na análise tome para si as forças curadoras da imagem arquetípica que ativará a energia do processo em que estão inseridos "analista-analisando-objeto material". O analisando é chamado a tomar parte ativa no processo e a reconhecer-se concretamente na transformação que vê acontecer em relação ao Objeto Material que ele e o analista manuseiam na sessão. Assim a experiência de totalidade se constela nas mãos que tocam o objeto material. (GOUVÊA, 1989, p.51).

Estamos nos referindo a um elemento cuja força simbólica favoreça o reconhecimento de que em si esteja petrificada a razão de ser da busca, o denominado "objeto do desejo", dotado da capacidade de despertar o ímpeto desejante tanto do analista quanto do analisando. Exercendo a função mediadora entre o simbólico de um e de outro, ele conflagra a abertura dialogal estabelecida no plano do "analista-objeto material-analisando", via articulação em significantes linguísticos mesmo, até o esgotamento destes - se for o caso - quando chegado ao universo do não dito.

Muito podemos especular sobre ao que recorrer para tal. Imaginariamente inúmeros artifícios teriam plausibilidade, caso utilizados enquanto recursos no caminho de nosso empreendimento. Entretanto, como o intuito por nós perseguido não é de permanecer no enquadre da verossimilhança, mas sim vislumbrar a tentativa de chegar à verdade do ser, faz-se mister a eleição de um objeto material radicalmente associado à constituição arquetípica com a qual nos identificamos. Nada melhor para nos remeter à massa originária de que somos formados, ao ventre, ao útero, ao seio donde saímos, senão o barro.

A abordagem bíblica corrobora a visão a esse respeito, e ela não pode ser desconsiderada se entendida à luz de uma imagem arquetípica gravada no interior do inconsciente coletivo de um povo cuja relevância é inegável. No livro do Gênesis encontramos a narrativa: "O Senhor Deus formou, pois, o homem do barro da terra." (Gn 2,7a). Há uma noção importante acerca da origem do ser humano, além do concernente ao seu fim, também ligado ao objeto material a que nos referimos dentro desta mesma tradição, quando nos é afirmado: "Pois tu és pó e ao pó retornarás." (Gn 3,19b).

$\mathrm{Na}$ esteira do objeto que é o barro, ocorre certa vinculação com os citados quatro elementos desde os Pré-socráticos considerados matrizes do universo: ar, água, terra e fogo. Há a associação ao sopro de vida, à maleabilidade muito própria da terra molhada enraizada na plasticidade da argila, à terra fria e ao oposto dela, o calor das mãos. Nas mãos o ser humano se coloca por inteiro, manuseia o material inconsciente da psique transformado em produções, em expressões reconhecíveis de suas vivências internas. Os complexos anteriormente inexprimíveis vão ganhando contorno e materialidade, uma significação emocional transmitida em concreto ao mundo da consciência.

Cai a mordaça aprisionante dos complexos que pareciam exercer certa força incapacitante de expressão. No caso, faltava saber qual a maneira apropriada de delinear isso, inviável nos termos habituais da verbalização, caríssimos ao ambiente terapêutico. Na forma de imagens da experiência encontramos o meio favorável objetivando exprimir o até o momento considerado inexprimível. A aposta recai no uso da linguagem não tanto da razão, mas da emoção; quando baixadas as guardas 
da resistência e derrubadas as censuras, aflorariam os elementos imaginários. Estes, a partir do encontro das mãos acaloradas com o barro altamente maleável, encontrariam as condições favoráveis para poderem vir potencialmente com inúmeras possibilidades, caracterizando o processo de criação, tecido em liberdade.

Da massa informe do substrato argiloso acalorado pelo manuseio humano, surge uma alteridade sobre a qual está projetada uma vida, mais precisamente a própria vida do analista e do analisando, repleta da capacidade de vir-a-ser, liberta dos condicionamentos da dureza peculiar à ordem do material. Concretiza-se a experiência de estar consigo mesmo na mão, no dar-se da incondicionalidade do ser da existência, tão capaz de assumir as mais variadas formas, tanto quanto o elemento que se apalpa, havendo algo de libertador nisso.

Favorece o processo a identificação inconsciente que estabelecemos com o barro, cuja explicação bastante pertinente remonta à concepção arquetípica da realidade. Existe nele o que é nosso, existe em nós o que é dele numa concepção muito além do científico apenas, englobando o que o mitológico, o religioso, o filosófico comunicam no tocante ao tema. Escatologicamente, em algum momento, estará mais evidente de maneira individual para nós essa nossa relação com o barro, até porque do pó somos feitos e ao pó retornaremos. Na hora derradeira, a do retorno a ele, misturar-nos-emos com ele, seremos um com ele, e no final de tudo seremos ele.

O uso do barro em psicoterapia nos abre à experiência de uma vida inteira, na dimensão cíclica bem peculiar a ela. A vida começa fria e informe, do chão; ganha um sopro de existência, um espírito, um sentido, dada a iniciativa de alguém em tocar nela, manipulá-la; é regada pelo ímpeto das vivências, acalorada pelas emoções, assumindo as mais variadas formas, até chegar a uma em que poderá enrijecer-se, garantindo sua solidez, mais precisamente relativa solidez, porque as necessidades conjunturais sempre exigirão permanente remodelação e, se for o caso, que a forma estabelecida seja desfeita para que se comece tudo outra vez. A vida é assim: ao final voltamos à terra, ao pó e nos tornaremos a matéria prima com a qual o ciclo se renova.

\section{CAPÍTULO 2}

\section{A BASE TEÓRICA JUNGUIANA}

Para a introdução do conceito de Arquétipo, faz-se necessário tomar por base o que Jung denominará "Inconsciente Coletivo". Este se distingue do Inconsciente pessoal, que traz consigo as camadas mais superficiais do inconsciente, cujas fronteiras com o âmbito da consciência mostram-se por demais imprecisas. Em tal nível, elementos que embora não estejam em conexão com o ego, facilmente atuarão no sentido de influenciar os processos conscientes. Suas experiências estariam agrupadas em complexos nos quais certos padrões ao serem amiúde reproduzidos mentalmente, 
seriam facilmente exteriorizados na esfera do comportamento, o que explicaria o fato dos distúrbios psíquicos encontrarem muitas das suas expressões na esfera do somático.

O "Inconsciente Coletivo", por sua vez, estaria no campo das camadas mais profundas do inconsciente, onde se encontram os fundamentos estruturais da psique, comum a todos, sendo depositário das experiências acumuladas por inúmeras gerações, advindas, inclusive, dos nossos ancestrais. Aqui, o que se experienciou filogeneticamente permanece restrito ao campo do inconsciente, como ocorre com o que ficou experienciado no âmbito do inconsciente pessoal, não havendo lembranças ou imagens de nada disso.

Nesta esteira é que se pode falar de outro conceito, o de "Arquétipo". Os Arquétipos são matrizes arcaicas que resultam do acúmulo de impressões superpostas remanescentes de certas vivências fundamentais armazenadas no interior do inconsciente coletivo. $\mathrm{Na}$ longa duração, experiências que vão se tornando típicas poderiam ter criado disposições inerentes à estrutura do sistema nervoso, que favoreceriam a construção de representações sempre análogas ou similares.

O Arquétipo seria expressão de energia psíquica concentrada, que, estando em potencial, atualizaria-se. Dessa atualização tem-se a imagem arquetípica, imagem essa que não é o Arquétipo, visto que ele é uma virtualidade. Deste dado lançaremos mão para compreender a maneira como a inserção do objeto material em psicoterapia poderia corresponder à aplicação deste modelo, dito arquetípico.

\subsection{OS ARQUÉTIPOS}

Denominamos Arquétipos os conteúdos do inconsciente coletivo (JUNG, 2014). Trata-se de tipos arcaicos, mais precisamente, primordiais, isto é, de imagens universais que remontam à nossa primitividade. Podem muito bem estar aplicados aos conteúdos inconscientes, dado ambos terem praticamente a mesma significação.

O conceito de Arquétipos está indiretamente aplicado às representações coletivas, desde que venham a designar especificamente aqueles conteúdos psíquicos ainda não submetidos à elaboração consciente, mas que ainda assim, desta elaboração, recebe influências. Suas manifestações imediatas em sonhos e visões aparecem de forma mais individualizada, com um detalhe: continuará representando essencialmente um conteúdo inconsciente, que ao se manifestar nas maneiras acima mencionadas já terá sofrido modificações mediante sua conscientização e percepção, assumindo matizes que irão variar de acordo com a consciência individual que os evidencia.

Jung (2014) assume o quão difícil é fundamentar psicologicamente a sua teoria, que talvez ficasse mais clara quando relacionada com o mito, o ensinamento esotérico e aos contos de fada. Quando dissemos todo esse panorama remontar à nossa primitividade, é porque se faria necessário voltar ao homem primitivo mesmo para poder tornar inteligível o que se propõe. 
O interesse do homem primitivo não estava nas explicações objetivas do óbvio. Havia uma necessidade praticamente irresistível advinda da alma inconsciente, segundo a colocação do próprio Jung (2014), que o impelia a assimilar toda experiência externa sensorial relacionada a acontecimentos anímicos:

Para o primitivo não basta ver o Sol nascer e declinar; esta observação exterior deve corresponder - para ele - a um acontecimento anímico, isto é, - Sol deve representar em sua trajetória o destino de um Deus ou herói que, no fundo, habita unicamente a alma do homem. (JUNG, 2014, p.14).

E, no caso, tais acontecimentos, ditos mitologizados, não representariam, de modo algum, alegorias destas experiências objetivas, eles seriam expressões simbólicas de todo um drama processado internamente e de forma inconsciente na alma, passíveis de serem apreendidas pela consciência humana através de projeção, porque espelhadas nos fenômenos da natureza. A projeção, a que se refere Jung, é tão radical a ponto de ter havido a necessidade de milênios de civilização para desconectá-la do objeto exterior. É citada a astrologia como exemplo. Outrora, em tempos antigos, considerada como scientia intuitiva (2014), passa a absolutamente herética por não prescindir das estrelas as atribuições psicológicas com as quais estariam envolvidas. Hoje, com todos os avanços científicos, quem acreditaria em astrologia? Isto porque relegada ao âmbito da superstição, da influência dos astros.

Não imaginemos, na leitura apressada de Jung, que ele esteja a fazer apologia à astrologia. Está em questão o fato do homem primitivo ser de uma subjetividade tal que é admirável nunca antes ter relacionado os mitos com os acontecimentos anímicos, e jamais ter cogitado que seu conhecimento da natureza fosse a linguagem, a roupagem externa, o veículo do processo anímico inconsciente. Exatamente por tratar-se de um processo inconsciente, é que se parece ter pensado em tudo, menos na alma, com a finalidade de explicar o mito.

Da alma advém todas as imagens das quais os mitos foram emergindo, dando mostras de que o inconsciente está em intensa atividade, como um sujeito ao mesmo tempo atuante e padecente. Nise da Silveira (1976) esclarece que embora Jung se exponha nestes termos, não pretende afirmar a existência de ideias inatas ou imagens inatas. Seu objetivo seria postular a existência de uma base psíquica comum compartilhada por todos os humanos, o que explicaria o porquê do aparecimento, em épocas e em lugares distantes, de temas idênticos nos contos de fadas, nos mitos, nos dogmas e ritos das religiões, nas artes, na filosofia, nas produções do inconsciente de um modo geral (sonhos, delírios dos loucos).

Os temas em consonância uns com os outros, expressos nas mais variadas épocas e pelos mais variados mecanismos, na compreensão ainda de Nise da Silveira (1976), trazem à tona a eclosão de imagens similares processadas por formas instintivas de imaginar, com referência a matrizes arcaicas onde, no dizer da autora: "configurações análogas ou semelhantes tomam forma." (1976, p.77). Neste enquadre surge o que podemos chamar de imagem arquetípica. 
Originada do que funcionaria como um nódulo de concentração de energia psíquica, e que por sua vez é denominado arquétipo, ela, a imagem arquetípica, não passaria da exteriorização de imagens interiores. Não se constituiria, portanto, a manifestação do arquétipo, que é unicamente uma virtualidade, resultante do acúmulo das impressões que vão se acumulando umas sobre as outras, decorridas de vivências típicas, fundamentais, repetidas incontavelmente na longa duração. Com isso seriam criadas disposições inerentes à estrutura do sistema nervoso que confluiriam para a produção de representações ditas sempre análogas ou similares (SILVEIRA, 1976).

Os arquétipos seriam determinados quanto à forma, não quanto ao conteúdo. Ainda assim, quanto à forma, seriam determinados de um modo muito limitado. No tocante ao conteúdo, seria qualificada uma imagem por arquetípica, também denominada imagem primordial, a correspondente à tomada de consciência, ao preenchimento com o material da experiência consciente.

No que concerne outra vez ao aspecto formal do arquétipo, Jung faz a comparação com o sistema axial de um cristal. Nele estará determinada a estrutura cristalina na solução saturada sem haver uma existência material; ficaria apenas a estrutura estereométrica, não a forma concreta do cristal particular. O exemplo é por demais ilustrativo, porque nos faz perceber que o arquétipo é um elemento vazio, possibilidade dada a priori da forma da sua representação. Concentrado de potencialidades inúmeras, evoca no psiquismo alta tensão energética com capacidade infindável de geração.

Interessar-nos-á o decorrente da carga em potencial atualizada, que produz conteúdo dentro da forma e se traduz em imagens, imagens que vem de dentro - vide os sonhos -, cuja formação haurida da energia psíquica, não se explica muito bem como se tem. Semelhante às transformações energéticas das quedas d'água em luz e da luz em calor, que em seus pormenores não se explica também.

Sabe-se haver neste tipo de abordagem o contato com o veículo das vivências típicas e fundamentais incrustadas nas profundezas do nosso ser: as imagens primordiais, interiores, que muito comunicam a nosso respeito. Dados os pressupostos mencionados anteriormente, a argila, objeto material inserido na psicoterapia, seria um suporte oportuno no qual a forma ganharia matéria e, por conseguinte, o imanipulável se transformaria em manipulável, o intratável em tratável. Desta maneira, damos abertura a aplicação de um modelo arquetípico de tratamento que corporifica analista e analisando, unindo o imaterial do simbólico inerente ao aspecto imagético aqui envolvido, ao material do objeto utilizado, remontando às realidades a que pertencemos: o espiritual e o corporal. Assim estaríamos nos pautando por uma visão integral do ser humano e apostando na implementação disso para o desenvolvimento da própria análise.

\subsection{UMA POSSÍVEL APLICAÇÃO DO MODELO ARQUETÍPICO}


Pensamos na aplicação de um modelo arquetípico, no trato psicoterápico, considerando a inserção do barro nas sessões de análise. Sua concretude, para quem o manuseia, precisa trazer à tona o sentimento de solidez que toca a realidade da existência, que evoca a eleição de um suporte cujo significado seja rico e capaz de comportar a voracidade das projeções humanas. Nesse movimento, o que se encontra sem forma no interior do sujeito ganha contornos bem precisos, é quando o imanipulável se tornaria manipulável e o intratável, tratável. Cabe o exemplo citado pelo professor Álvaro quando do acompanhamento de um analisando seu:

Um analisando meu, quando percebeu que ao juntar dois olhos, um nariz e uma boca, obedecendo às disposições simples das formas de seu rosto, Ihe dava, no barro que manuseava, um novo rosto, um concreto rosto, viveu um grande momento de criação. A Gestalt que a máscara que criara lhe insinuava proporcionara-lhe um grande prazer, acompanhado do sentimento de solidez que the possibilitou mais tarde compreender e amenizar um forte complexo de inferioridade. (GOUVÊA, 1989, p.84).

A revelação desse tipo de verdade interior tão profunda vem do trabalho experimental que o contato com a argila propicia, com abertura à experiência de si que se descortina. $O$ instante da consciência acontece quando o analisando se surpreende experimentando-se a si mesmo e não pura e simplesmente o objeto, o que acontece dentro de um processo iniciado com a expressão dirigida e culminado na livre expressão.

Em tempos ordenados, no trabalho de expressão dirigida, seria pedido ao analisando a confecção de máscaras de argila. Ao sugerir o rosto, o analista propõe a insinuação de algo que vem de fora e que seria encaminhado para o interior do sujeito, com o que se deixaria ali dentro uma marca de consciência. Quando o espaço da consciência já estivesse virtualmente elaborado no mundo interno do analisando, a condição para o contato com a realidade concreta do mundo externo estaria preparada, fluindo em arte. Aí estaria garantida uma exposição sem que ficasse agredido o seu silêncio, seus medos, com o devido resguardo de sua alma.

A revelação, neste ensejo, aconteceria dentro de um processo de aproximação gradual do centro da alma, em que só veria quem tivesse olhos para ver, porque na busca quase que exclusivamente individual pelo âmago da identidade, no profundo do ser, haveria a pretensão de encontrar o que em nós anseia por consciência: "Trata-se da evolução da consciência milímetro por milímetro em ritmo de criação." (GOUVÊA, 1989, p.84). Verificamos com isso o ambiente propício ao trabalho de livre expressão. Empreendida anteriormente, na expressão dirigida, a tarefa de levar para dentro os determinantes externos agora estará firmada, o que assegura a expressão dos determinantes internos, que fazem aflorar as imagens das emoções advindas na maioria das vezes do inconsciente profundo.

Cadenciado o movimento de fora para dentro e de dentro para fora, do consciente para o inconsciente e do inconsciente para o consciente, fica difícil de especificar o que prevalece neste vai e vem. Presumimos, dependendo da situação do paciente, poderem surgir máscaras oriundas de 
complexos coletivos. Tais complexos seriam hauridos de conquistas no sentido da harmonização de atitudes encaminhadas pelo analisando, seja a partir da orientação do analista (consciente para inconsciente), seja a partir do trabalho de livre expressão no barro, por meio do que é possível o acesso a um tipo de conteúdo que extrapola os limites do inconsciente pessoal, chegando ao nível do alcance do inconsciente coletivo.

Há, claro, o processo transcorrido capaz de viabilizar o encaminhamento para esta direção, com todo um desenrolar de cadeias associativas passíveis de serem feitas com base no uso da matéria-prima escolhida, a argila. Ela é um correspondente do mundo externo no qual o mundo interno encontra o suporte favorável à sua expressão, deixando vestígios dos estados afetivos, das forças psíquicas atuantes que se equilibraram para dar origem a imagens concretas de formulações intuitivas que precisam, segundo Gouvêa (1989), inteirar-se do fenômeno global da consciência, sem prejuízo ao caráter pessoal da representação que veio à tona projetada pelo próprio inconsciente em função de necessidades arquetípicas.

Remontaríamos aqui a experiências subjetivas individuais em contato com uma subjetividade maior, ou o encontro entre inconsciente individual e inconsciente coletivo. Nise da Silveira recorre a Neumann (1955, p.12 apud SILVEIRA, 2015, p. 155) acerca dessa possibilidade ao fazer remetimento a misturas e combinações realizadas no interior das matrizes arquetípicas em algum momento do desenvolvimento da consciência, quando esta ainda não obteve a capacidade de fazer as necessárias distinções e diferenciações. Nós nos encontramos neste enquadre em nossa pretensão de aplicar uma ação terapêutica capaz de fazer emergir os conteúdos das camadas mais profundas da psique, que trazem a nossa primitividade, com tudo o que a engendra, quando chegamos à base psíquica comum compartilhada por todos, justificando a noção de arquétipo, da fonte donde beberam muitos dos contos de fadas, dos mitos, dos dogmas e ritos das religiões, das artes, da filosofia, das produções do inconsciente de modo geral - sonhos das pessoas normais e delírios dos loucos, cujos temas se mostraram idênticos apesar da distância de épocas e lugares.

Isso não apenas dá viabilidade à realização de um trabalho desta natureza, que se pauta pelo modelo dito arquetípico, como também o dota de cientificidade, por presumir essa base psíquica comum sobre a qual está assentada a possibilidade da execução de um tratamento psicoterápico com pretensões universais, dado que para ser científico precisa valer para todos e estar abalizado por leis universalizantes. Gouvêa (1989) expõe outro detalhe dentro deste processo, o da abertura à criatividade. Isto é: "A formulação científica com base numa abertura criativa, profundamente embebida pela imagem arquetípica da totalidade." (GOUVÊA, 1989, p. 108)

A criação tem uma finalidade no interior deste empreendimento. A referência a imagens simbólicas carregadas de conteúdos inconscientes oriundas do trabalho de manipulação da argila precisa estar amarrada a certo propósito. Ensejamos ultrapassar a nuvem dos conteúdos arquetípicos não unificados para terapeuticamente podermos fazer a conexão com o real possível. $O$ instrumental oferecido confere tanto ao analista quanto ao analisando a compreensão necessária para interferirem no processo. Basta esclarecer que ao analista cabe manusear o barro juntamente com o analisando. 
Em expressão conduzida, fazendo as máscaras com o referido material, o analista estaria com a mão na massa, mas com a atenção voltada para o analisando, ajudando-o - se for o caso - apenas para providenciar mais argila, papel, etc., sem tocar na máscara que está sendo elaborada por ele, e, em expressão livre, nem no barro é recomendado que toque. O contrário disso só é benéfico no caso do término da tarefa ou quando o analista sente ser necessária uma participação mais ativa junto ao analisando. Nesta forma de trabalhar, a criação é em conjunto e, de tal maneira, o caminho é aberto a muitos jogos de relações que podem vir a ser criados entre os dois na tentativa de descobrirem formas terapêuticas concretas capazes de propiciarem o encontro das imagens existentes por detrás das emoções, a fim de dar-Ihes forma e existência. Nada melhor do que a práxis, sobre a qual discorreremos agora, na tentativa de mostrar os desdobramentos do tipo de atuação por nós qualificada aos moldes da abordagem dita arquetípica que, para além de se revelar possível, insinuase também viável.

\section{CAPÍTULO 3}

\section{"PIPA": O ENCAMINHAMENTO A UMA PRÁXIS}

Neste capítulo temos a pretensão de mostrar para onde confluiu a proposta inicial de pensar uma psicoterapia de cunho junguiano, com a aposta da inserção do objeto material, especificamente o barro, para em meio a esta tridimensional relação cogitar a possibilidade de ter nas mãos a própria neurose.

Antes, conforme o itinerário empreendido até aqui, foram vistas as significações desta iniciativa para o trato psicoterápico, e, à luz do conceito de "Arquétipo" construído por Jung, buscou-se a fundamentação teórica que fosse preenchendo a estrutura desenvolvida no curso deste trabalho. Postulou-se o encaminhamento a uma práxis capaz de dar conta da aplicação de um modelo dito arquetípico.

A práxis, a que nos referimos, ganha corpo no projeto desenvolvido pelo Professor Álvaro de Pinheiro Gouvêa, o "PIPA" (Produções do Imaginário e Psicologia Aplicada), sobre o qual nos debruçaremos neste Terceiro Capítulo. De certo modo, foi eleita uma via de acesso com a finalidade de permitir encontrar o eixo condutor da proposta à práxis psicoterapêutica tridimensional por nós abordada, que tem no PIPA uma referência original e esclarecedora para qualquer outra atividade a ser desenvolvida nestes mesmos termos.

\subsection{TEORIZANDO A PRÁXIS E BUSCANDO SUA FUNDAMENTAÇÃO}


Imbuídos das discussões teóricas em sala de aula sob a coordenação do professor Álvaro Gouvêa, inscritos na disciplina de Estágio Básico II do curso de graduação em Psicologia da PUCRIO, no primeiro semestre de 2015 , fomos encaminhados ao exercício da práxis em campo por meio da inserção no projeto "Produções do Imaginário e Psicologia Aplicada", designado pela sigla "PIPA".

Foi-nos proposta a participação em uma vivência em sala de aula, realizada entre nós professor, alunos e alguns monitores do projeto - como condição sine-qua-non para a ida ao campo. Tomamos ciência, de uma forma vivencial, das etapas do método empregado nas sessões do PIPA, em que se coloca no primeiro momento o trabalho com o corpo, no que concerne principalmente a questão do equilíbrio; no segundo momento, atividade de respiração; para, no terceiro momento, ser empregada a manipulação da argila, em um movimento que vai da expressão conduzida à expressão livre.

Pela expressão conduzida, levam-se os participantes a confeccionar "máscaras de argila" e pela expressão livre dá-se a permissão para que a argila seja manipulada da forma que melhor aprouver. $O$ intuito é fazer emergir inicialmente a construção de imagens concretas que hão de ser em seguida acompanhadas e examinadas por meio da intervenção verbal sobre elas, segundo o esclarecimento de Gouvêa (1999).

Digamos que, pedagogicamente, fomos imersos no universo teórico do projeto, na sua metodologia, enriquecendo-nos com a bagagem conceitual e paradigmática que serviria como instrumental para a aplicação do método nas suas etapas, em vista da utilização do mesmo no campo. Lançamos mão da distinção entre metodologia e método feita por Edgard Morin (1986, p.29 apud GOUVÊA, 1999, p. 129) para falarmos nestes termos. O referido autor compreenderá "metodologia" como o guia a priori a orientar a investigação, ao passo que o método, que é desprendido do exercício da práxis, será um auxiliar da estratégia, compreendendo elementos programados, ou seja, metodológicos, porém sem se fechar necessariamente à descoberta e à inovação.

O propósito fundamental do trabalho é introduzir práticas analíticas que favoreçam o contato direto do analista e do analisando com os objetos reais, a começar pelo próprio corpo, na perspectiva de construir um discurso sobre a presença do objeto, mas não na sua forma grosseira, diríamos assim, no modo como é captado pelos sentidos pura e simplesmente. Neste contexto, não se tem a pretensão, por outro lado, de se rejeitar em absoluto o objeto na sua forma ideal; pretende-se, por sua vez, o estabelecimento de um equilíbrio técnico do objeto, no intuito de estabelecer um novo campo para a atividade analítica, estruturado em torno da noção de Objeu.

O termo Objeu foi criação do poeta francês Francis Ponge. Não é um termo de origem francesa, todavia um neologismo que dá conta de uma tentativa de tomar o objeto na sua dimensão simbólica, que funde em si o aspecto sensorial e ideal que o envolve. Tal fusão é decorrente da interação entre sentidos, intuição, sentimentos, sensações, emoções, do circuito prazer/desprazer, do próprio pensamento, donde se estabelece a relação de objeu, a mobilizar novas representações (representação de objeu). Concorre-se, desta maneira, para a criação do símbolo vivo, fundado no 
conceito de imagem-ação, criando condições para a integração da imaginação sensorial à imaginação verbal:

\begin{abstract}
A psicanálise, na condição de método psicoterápico, não pode se limitar apenas a imaginação verbal. Sabe-se que o verbal como método de exploração do inconsciente tem se revelado insuficiente. Na verdade, para pôr em andamento os objetos mentais é preciso que o analista aprenda a utilizar a imaginação material como via para a construção do simbólico e traçando uma metapsicologia com base neste tripé: sujeito, objeto-ideia via objeto real. (GOUVÊA, 1999, p. 68)
\end{abstract}

Importa devolver o objeto real à práxis analítica, impedindo que o subjetivismo nefasto que toma conta da noção de objeto em psicanálise possa manipular de maneira controvertida o objeto real e o brincar analítico. A psicanálise, nestes termos, precisa garantir a coesão dos objetos, tentando viabilizar uma abertura para o jogo com o objeto real, uma vez que o que se deseja traz consigo a exigência de ser referenciado no mundo externo. Com isso queremos dizer que a utilização de um objeto concreto como instrumental de trabalho do analista pode servir como estimulante para o psiquismo no sentido de favorecer o contato com o seu mundo inconsciente, para que seja dado o devido valor à suas imagens mentais e para aprender a manipulá-las na qualidade de objetos internos.

O objeto concreto, na relação dita acima, fixa de algum modo um limite para a metáfora da ausência, subordinando o desejo a existência do objeto externo. Nesse caso o objeto imaginário interage com o objeto real, que por sua vez é moldado pelo conceito, transformando-se em objeto do jogo analítico, tornando possível quebrar a primazia da palavra pela criação deste novo enquadre, no qual a linguagem sensorial importa tanto quanto a linguagem verbal. Ligando simultaneamente o verbal e o sensorial por intermédio de um objeto concreto, fazemos emergir um novo tipo de jogo analítico que viabiliza o manusear da emoção e a consequente elaboração do acontecimento traumatizante.

Para isso é preciso fazer que o analisando utilize o objeto externo, na relação de objeu, como suporte do eu para poder lidar duplamente com seu problema emocional. Primeiro, coloca-o em contato com os objetos fantasmáticos pela via do jogo com os objetos externos, tentando dar-lhes um contorno objetivo. Depois, o temor de encarar a neurose seria substituído pelo sentimento de domínio sobre a imagem manuseada. Com isso faz-se que o analisando, lidando com imagens concretas do distúrbio emocional, petrificando sua neurose no objeto material, tenha esta mesma neurose nas mãos, assumindo-a como objeto do jogo, de modo que brincando com o que the angustia estaria muito mais disposto a superá-la. No mais, analiticamente falando, essas imagens petrificadas no objeto real não exporiam toda intimidade do analisando, mas apenas evidenciariam os contornos de sua subjetividade, insinuando os desejos inconscientes.

Numa alusão ao fort-da descrito por Freud, a utilização do objeto material - no trabalho analítico -, em vista da relação de objeu, corresponde ao retorno do carretel. Tem-se a 
experimentação do poder de jogar com os objetos do mundo descobrindo-se como sujeito de ação. Esta prática garantirá a tridimensionalidade para $\circ$ ato analítico, possibilitando o contato com 0 terceiro elemento da relação, permitindo ao analisando viver a totalidade da experiência originária, englobando também a dimensão ativa do jogo.

A escolha da argila como terceiro regulador neste processo é bastante sugestiva, pela força simbólica trazida consigo. Ela está presente de forma mitológica em inúmeras tradições, inclusive na tradição bíblica, remontando às origens, tomada como matéria prima do cosmos. Nós a referenciamos como uma espécie de placenta da mãe-natureza, que no enquadre analítico propicia ao analisando o espaço concreto para dar continuidade ao brincar uterino, daí considerarmos a argila anterior à fase anal. Neste sentido, a argila entra no imaginário como um fator externo e interno ao mesmo tempo. Na relação de objeu, por intermédio da argila, será dito: "As mãos e os objetos externos estão a serviço de uma linguagem viva e porosa que nasce das profundezas de uma psique que quer se experimentar na práxis." (GOUVÊA, 1999, p. 123)

Já criamos condições para afirmar que expressão livre e expressão conduzida, as duas direções básicas a serem seguidas no nosso método de trabalho e das quais falamos anteriormente, seguirão no setting os moldes do fort-da. Ao fazer o analisando cunhar a imagem inconsciente na argila, oferece-lhe a possibilidade de ter acesso ao objeto perdido de uma maneira criativa. $O$ movimento proposto obedece à ordem gradativa da expressão conduzida para a expressão livre, raramente o contrário.

Por meio da confecção de "máscaras de argila" em expressão conduzida segue-se o trajeto marcado pela consciência objetal que age de fora para dentro no indivíduo, fixando e registrando o que existe de dispersivo no inconsciente. Consolida-se desta maneira o ponto de apoio por meio do qual se fará possível por parte do analisando dar o salto em expressão livre para entregar-se mais livremente aos meandros inconscientes de suas emoções: "Na prática, trata-se simplesmente de deixar fluir a libido, familiarizando o analisando com o relacionamento com os objetos de fora de sua área de controle". (GOUVÊA, 1999, p. 128)

Máscaras em expressão conduzida e imagens em expressão livre formam os dois polos reflexivos de um mesmo enquadre analítico, em que se pretende estabelecer o ponto de encontro possível entre o princípio de realidade e o princípio de prazer como caminho para o processo de cura analítica, que para ser alcançada demanda a entrada em outra fase do processo, da intervenção verbal sobre as imagens concretas que foram construídas.

A esta intervenção verbal damos o nome de interpretação de objeu. Por ela o analisando vai até as raízes do simbólico, esforçando-se para penetrar na imagem pela palavra e pelos sentimentos, no intuito de resgatar o discurso perdido em meio às metáforas perniciosas veiculadas pela linguagem da neurose. Assim sendo, o analisando fala livremente sobre aquilo que sentiu durante a fabricação das imagens pelas suas próprias mãos, dando um sentido estético ao objeto do desejo, na mesma medida em que desmascara a função da falta enquanto estratégia para o ato analítico. 
Evidencia-se, portanto, uma metodologia que permite ao analista tratar a neurose pela alternância dialógica entre os dois polos do objeto: de um lado, o objeto de fascínio, de paixão, de projeção, e, de outro lado, a presença de um objeto concreto, real, a servir como suporte para ajudar o analisando a lidar com seus objetos fantasmáticos, ao lhe permitir de algum modo manipulá-los e por esta manipulação ter certo controle sobre eles.

\subsection{A INSERÇÃO DO PROJETO: UMA REFLEXÃO}

As aulas do Professor Álvaro na disciplina de Estágio Básico II, seguidas da inserção no PIPA, foram uma aventura inusitada dentro do universo teórico e intelectualista em que estamos envolvidos no meio acadêmico. Sem abrir mão do rigor "científico" em nossas elaborações, demos espaço para o imaginário, para a arte e o lúdico não serem apenas pensados, mas acima de tudo experimentados. Quando da vivência em sala de aula que preparou nossa ida ao campo e na ida ao campo propriamente, os conceitos se materializaram e se desdobraram bem diante dos nossos olhos; eles ganharam corpo em nossas mãos, se considerarmos o que a manipulação da argila como uma das etapas do método causou em nós.

Estivemos imersos em uma experiência que se desdobrou para além dos muros da universidade, levando-nos ao encontro do indivíduo no ambiente que Ihe é próprio, ali onde sua vida acontece, em um trabalho mais preventivo que de emergência no âmbito da saúde mental. O projeto tem a iniciativa louvável de deixar o espaço confortável e favorável da academia, diferindo, por exemplo, de um trabalho como o do SPA (Serviço de Psicologia aplicada) da PUC-Rio, no qual os assistidos são desterrados dos seus locais de vivência, acorrendo aos nossos serviços quase sempre em situações agudamente emergenciais para serem atendidos nos consultórios-escola da instituição.

Decorre deste movimento o sentido de autoestima por parte de quem é assistido, pois se o outro se interessa por ele e Ihe vai ao encontro, isso aguça a curiosidade a respeito de si mesmo, favorecendo o desejo de mergulhar em sua própria subjetividade; e como a nossa proposta tem uma índole mais voltada para o trabalho em grupo, também propicia o interesse por perscrutar a subjetividade alheia. Nota-se, neste ensejo, a preparação para o reconhecimento de uma subjetividade que não seja solipsista, isolada do mundo, pensada de modo independente das demais, porém na relação com outras subjetividades a sua volta, inserida no meio social.

Estamos diante de uma empreitada em que todos os envolvidos são passíveis de favorecimentos. Nos moldes atuais, atuando em meios socialmente desfavorecidos, o projeto incute tanto nos psicólogos já formados quanto nos futuros profissionais da Psicologia a responsabilidade social que não deve faltar em todos nós enquanto cidadãos, sem deixar de nos favorecer também pelo acúmulo de experiências que agregamos ao hall de conhecimento que é necessário para uma boa prática profissional. Ganha quem é assistido, por ser contemplado pela participação em um programa que viabiliza a qualidade de vida por meio de ações preventivas na esfera da saúde mental 
e ganha também a Psicologia, em razão de ter a sua ação ampliada e promovida em meios em que naturalmente não se faria presente com tanta facilidade.

\subsection{SUGESTÕES EM VISTA DA PRÁTICA REALIZADA}

Estive envolvido nas atividades de campo da disciplina de Estágio Básico II nos dias 31 de março, 07 de abril e 14 de abril de 2015, no interior da comunidade Vila Parque, nas imediações do Parque da Cidade, na Gávea. Atuei juntamente com a monitora Chloe D’Archemont, em sessões ministradas na parte da manhã, que iam de $9 \mathrm{~h}$ até $10 \mathrm{~h} 30 \mathrm{~min}$.

Já havia verificado, na ocasião da vivência em sala de aula, o quanto o método é criativo, fazendo a junção de atividades já consolidadas em outras frentes no que tange ao trabalho com o corpo, exercício de respiração e a manipulação da argila objetivando aqui uma ação terapêutica.

Ocorre a associação de três tipos de ações como crescentes em um processo que leva o paciente primeiro a trabalhar o equilíbrio corporal, depois a autorregulação pelo processo respiratório, para em seguida fazê-lo manipular a argila com o propósito de tornar possível a entrada e a saída de si, respectivamente, pelo exercício que vai da expressão conduzida à expressão livre. Isso considerando que as máscaras em expressão conduzida ajudam a fixar no inconsciente o que até então se encontra disperso, enquanto o que se realiza em expressão livre, depois de estabelecido o ponto de apoio por meio do momento anterior, favorece ao analisando dar o salto para colocar para fora suas emoções.

Não perdemos de vista o fato de expressão conduzida e expressão livre serem o ponto de toque entre dois princípios fundamentais nos quais, psicanaliticamente falando, estamos engendrados: o princípio de realidade e o princípio de prazer. Não é de interesse sobrepor um ao outro, contudo manter viva a tensão entre ambos para o estabelecimento de um equilíbrio entre estas forças antagônicas, equilíbrio esse cuja busca já se enuncia no momento inicial de trabalho com o corpo, e que tem no exercício de respiração a fase transicional de um processo de equilibração corporal até chegar a equilibração psíquica.

É magnífico nos darmos conta disso: antes nós, os envolvidos neste processo, que outros. Coloco-me desta maneira para sugerir que o método seja patenteado o quanto antes, caso até agora não tenha sido. Minha preocupação é porque vejo a possibilidade do seu uso de forma empreendedora. O professor Álvaro, ele mesmo, em uma de suas aulas, destacou ter sido sinalizado neste aspecto pelo setor de empreendedorismo da PUC-RIO, que serve de incubadora de empresas em nosso meio.

A experiência que tive no campo deu-me a impressão de que manter sempre as mesmas crianças ou as mesmas pessoas submetidas em todas as sessões ao mesmo método torna-se algo cansativo ao longo do tempo. Não descarto o valor da experiência adquirida, servindo como uma espécie de laboratório para as nossas equipes de trabalho e para o próprio professor. A minha 
sugestão é de fazer do PIPA algo sazonal e, por conseguinte, mais atrativo, inclusive economicamente para quem tem a pretensão de se dedicar a ele.

Vejo o PIPA não como sendo um fim em si mesmo, mas como um meio, sem que ele perca a dimensão preventiva para qual foi pensado. No meu modo de ver, este tipo de trabalho pode ser um instrumental importante para favorecer a descoberta da melhor alternativa de tratamento psicoterápico, em virtude de colocar em relevo o lado lúdico que deixa o analisando mais livre e, consequentemente, mais exposto. No lado do empreendedorismo, vislumbro o PIPA associado ao processo de coaching, como uma ferramenta diferenciada a ser oferecida a grupos, empresas e pessoas que queiram elevar o desempenho aumentando os resultados positivos.

O processo de coaching leva o cliente a novos entendimentos, alternativas e opções capazes de fazer com que ele amplie suas realizações e conquistas. Considerando que este tipo de atividade combina práticas e procedimentos distintos, visando dar suporte às pessoas para que sejam capazes de formular promissores objetivos e os perseguirem da melhor maneira, o PIPA poderia ser um instrumento importante nesta empreitada. No caso, o seu caráter holístico que integra a pessoa consigo mesma e com o mundo à sua volta, no exercício de equilibração que sugere, poderia se aproximar satisfatoriamente com a proposta oferecida pelo coaching, trazendo à tona a sua aplicação mais arrojada empreendedorísticamente falando.

\section{CONCLUSÃO}

A proposta que nos foi apresentada ao longo deste percurso abre-nos uma rota alternativa no trabalho analítico que parecia até o momento estar fechada, por conta do tradicionalismo vigente neste âmbito. Muito contribuiu para isso a base teórica psicanalítica de cunho junguiano, sedimentando as bases que propiciaram pensar a inserção do objeto material neste tipo de trabalho em termos de uma experiência constituinte do ser humano, dita arquetípica, desdobrada para um modo de interpretação deste terceiro elemento no jogo psicoterápico denominada de objeu. Com isso, estabelece-se a tridimensionalidade da relação analítica, fazendo emergir o suporte que faltava entre analista e analisando para dar maior fluidez ao processo de descarga das energias pulsionais.

Há de convir que a abordagem em questão opta pelo caráter lúdico no trato com o objeto externo na referida interpretação de objeu, sem prejuízo de qualquer natureza para o exercício da psicanálise. A leveza na qual se desenvolve a tridimensional relação por conta da "ludicidade" em que está engendrada, introduz nas práticas terapêuticas o brincar analítico, permitindo ao analisando tomar de forma descontraída as causas de suas neuroses, dissipando o temor de encará-las de frente.

Faz-se mister considerar a viabilidade deste método de trabalho, com amplo campo para desenvolver-se, inclusive do ponto de vista do empreendedorismo. A favor há o terreno fértil do meio 
acadêmico, no qual se pensa e repensa suas práticas, e a colaboração de todos os envolvidos a contribuírem para a ampliação dos horizontes desta linha de pesquisa.

\section{REFERÊNCIAS BIBLIOGRÁFICAS}

BACHELARD, G. A Filosofia do Não, O Novo Espírito Científico, A Poética do Espaço. Coleção Os Pensadores. São Paulo: Editora Abril, 1984.

BRENNER, C. Noções Básicas de Psicanálise. Rio de Janeiro: Imago, 1997.

ELLIOT, A. J. A Linguagem da Criança. Rio de Janeiro: Zahar, 1981.

GOUVÊA, Álvaro de Pinheiro. Sol da Terra: O Uso do Barro em Psicoterapia. São Paulo: Summus, 1989.

A Tridimensionalidade da Relação Analítica. São Paulo: Editora Cultrix, 1999.

$\overline{15 / 05 / 12}$

A Evolução da Terapia Ocupacional. Revista PSIQUE. Edição Especial nº 7. p. 24-29,

JUNG, Carl Gustav. Os Arquétipos e o Inconsciente coletivo. Trad. Maria Luiza Appy, Dora Mariana R. Ferreira da Silva. 11 ed. Petrópolis: Vozes, 2014.

Petrópolis: Vozes, 2017.

Os Fundamentos da Psicologia Analítica. Trad. Araceli Elman, Edgar Orth. A Energia Psíquica. Trad. Maria Luiza Appy. 14 ed. Petrópolis: Vozes, 2013.

A Prática da Psicoterapia: Contribuições ao Problema da Psicoterapia e à Psicologia da Transferência. Trad. Maria Luiza Appy. 16 ed. Petrópolis, Vozes, 2013.

SCHULTZ, Duane P.; SCHULTZ, Sydney Ellen. História da Psicologia Moderna. Trad. Marilia de Moura Zanella e Suely Sonoe Murai Cuccio. São Paulo: Cengage Learning, 2012.

SILVEIRA, Nise da. Jung: Vida e Obra. 5 ed. Rio de Janeiro: José Álvaro Editor / Paz e Terra, 1976. 


\section{APÊNDICE \\ RELATÓRIOS DE ESTÁGIO SOB A SUPERVISÃO DA ALUNA MONITORA CHLOE D'ARCHEMONT NO CAMPO}

Do primeiro dia, 31/03/15, na Vila Parque, de 9h às 10h30min.

Iniciamos com 5 crianças: 4 meninas e 1 menino, com idade entre 7 e 8 anos. Uma das meninas saiu logo no início, quando ainda estávamos introduzindo a sessão, pois a mãe chegou antes do horário para buscá-la. Em seguida, depois do primeiro momento, do trabalho com o corpo, mais duas meninas também saíram, em virtude da responsável por ambas, mãe de uma delas, ter alegado não poder esperar. Cabe ressaltar que uma das meninas insistiu veementemente para permanecer, sem alcançar a permissão para tal.

Breno e Clara permaneceram até o final: ele, com 8 anos de idade, e, ela, 7. As crianças como um todo, inclusive as que saíram no início, estavam muito dóceis. Vimos uma disposição em todas elas para deixarem-se envolver pelas fases do processo com muita seriedade, mas só conseguimos constatar efetivamente isso nas que chegaram ao fim da sessão.

Trabalhamos intensamente a questão do equilíbrio no primeiro momento, explorando cada movimento sem pressa e com toda calma e tranquilidade, com as duas crianças correspondendo a tudo que era solicitado. Sem qualquer tipo de intercorrência passamos para o segundo momento, o do trabalho com a respiração. Deixamos fluir o ar que entra e o que sai, pedindo total abstração no concernente aos sons à nossa volta para ficarmos concentrados unicamente no movimento do ar em nós. Antes de passarmos para a manipulação da argila, eu e Chloe começamos a nos dar conta de que o Breno controlava por intermédio do seu relógio de pulso o tempo de todas as fases da atividade. Percebemos não ser por pressa de ir embora, mas pela ansiedade de querer saber o que viria após cada tarefa e para chegar logo ao trabalho com a argila também, visto ser a sua primeira sessão.

Conforme o ordenamento, sugerimos a confecção de máscaras de argila, fomentando o trabalho de expressão conduzida, para em seguida darmos a abertura para manipularem a argila da forma que bem entendessem em expressão livre. Breno não fez máscara em momento algum, limitou-se a ficar o tempo todo apertando a argila, e quando já estávamos para finalizar o trabalho com as mãos para falarmos sobre o que elaboramos, ele fez rapidamente uma bolinha e a apresentou na tábua de exposição colocada no centro da nossa roda. Clara, por demais tímida ao longo de tudo o que fizemos, do trabalho com a argila em diante soltou-se surpreendentemente, mostrando maior agitação e quebrando o silêncio que lhe acompanhou desde o início.

Breno, pelo que a aplicação do método nos veio a mostrar, parece viver entre a tensão da norma e o desejo de liberdade, reproduzindo desde já o choque existente entre o princípio de 
realidade e o princípio de prazer. Vimos isso na necessidade por ele apresentada de controlar o tempo de tudo, e no meio disso tentar assegurar a sua autonomia manipulando a argila não da maneira sugerida, porém da maneira mais satisfatória para ele. No mais, mostrou-se prisioneiro do tempo, elemento de enquadre a chamar-Ihe à realidade, visto que antes do tempo esgotar veio a fazer rapidamente o sugerido, com mostras de grande ansiedade para acabar logo o que tinha de ser feito como solicitação externa, para em seguida verbalizar sobre a vivência. Clara, por sua vez, foi a prova real de como a relação de objeu no trato com a argila permite liberar as emoções e dar o salto para os desejos aprisionados, visto o quanto se soltou depois deste momento. Ambas as falas, quando da exposição verbal, vieram ao encontro destas perspectivas.

Do segundo dia, 07/04/15, na Vila Parque, de $9 \mathrm{~h}$ às 10h30min.

Estiveram presentes 3 crianças, 1 menino e 2 meninas. Duas das crianças haviam participado da sessão anterior: Breno e Clara. Integrou-se ao grupo neste dia uma menina chamada Liz, de 8 anos de idade. Terminamos o primeiro momento, o de trabalho com o corpo, com as crianças bastante agitadas, com o comportamento bem diferente do que manifestaram quando nos encontramos anteriormente, quando tudo ainda era uma surpresa, quando ainda não se sentiam familiarizados entre si, conosco (Chloe e eu) e com o método de trabalho.

Foi difícil manter a concentração das crianças na etapa subsequente, no exercício de respiração, pois estavam mais entregues a brincadeiras entre si e às implicâncias umas com as outras, que à tarefa a elas proposta. Não obstante as dificuldades, conseguimos terminar satisfatoriamente a atividade.

Quando do trabalho com a argila, Liz, a menina que vinha pela primeira vez à sessão, surpreendeu-nos. Da dispersão quase que absoluta manifestada desde o início, sobreveio uma grande concentração, de modo a nem parecer a mesma criança. Na manipulação da argila em expressão livre, ela confeccionou a representação de 2 bolos, sendo um maior e outro menor. Disse ser o maior para ela e o menor para a mãe, e assim gostaria de fazer para ao mesmo tempo exteriorizar amor e insatisfação para com sua genitora. Oferecer bolo por si só seria uma maneira de comunicar o amor, mas sendo este menor que o dela, segundo as palavras da própria Liz, neste gesto ela deixaria claro o quanto ela fica infeliz por ter que permanecer mais tempo com a avó que com a mãe propriamente, em virtude da mesma trabalhar fora.

Breno manteve a mesma postura da sessão anterior, confeccionando mais uma vez ao final desta etapa do processo a tal bolinha, e às pressas, somente para de última hora corresponder às exigências externas de fazer algo com a argila. Antes disso, ele a manipulava amassando-a desconexamente com as mãos. Com o que averiguamos, constatamos que se confirma de algum modo as nossas conclusões a seu respeito descritas no relatório do dia 31/03. 
Clara elaborou na argila, segundo ela mesma disse, uma pedra protegida por uma espécie de parede, tirando esta inspiração de um desenho que ela assiste. Falou a menina que gostaria de ser forte como a pedra e ainda por cima protegida por algo que pudesse conter todos os ataques, algo como uma parede mesmo. Tendo falado em seguida de tiros na comunidade onde mora e da tensão que na ocasião estavam vivendo por lá, presumimos ter sido a sua elaboração uma forma de expressar o clima de insegurança por ela vivenciado.

Do terceiro dia, 14/04/15, na Vila Parque, de 9h às 10h30min.

Foi uma sessão bastante conturbada, em razão de ter chovido ao extremo. Chloe chegou um pouco atrasada, e, das 4 crianças que compareceram, apenas uma permaneceu, a Clara. Com ela iniciamos o trabalho com o corpo, como de costume chamando a atenção para a questão do equilíbrio. Passamos para o exercício de respiração, tendo a Chloe dito ser esta etapa do método a que mais lhe apraz. Desta maneira, neste dia, ficamos mais tempo em tal atividade.

Quando do trabalho com a argila, Chloe sugeriu que fizéssemos algo referente a família. Ela, neste ensejo, fez cinco bonequinhos sem boca, em que quatro seriam do sexo feminino e um do sexo masculino. Evidenciou ser a sua configuração familiar, na qual o único homem é o pai, tendo a mãe e as duas irmãs, juntamente com sua pessoa, compondo as mulheres da casa. Foi justificada a ausência de boca no que fizera para tentar expressar a falta de diálogo em seu lar. Embora morem todos na mesma casa, falta comunhão, partilha, reciprocidade e até mesmo verdadeira proximidade entre os seus.

Clara confeccionou na argila a representação de uma mulher deitada em uma cama. Ao verbalizar sobre o que realizara, disse ter tentado representar ela mesma deitada na cama da sua mãe. Confessou ser muito malcriada com a genitora, decorrendo disso alguns castigos sofridos. Ainda assim, manifestou não ficar chateada porque quando tenta se colocar no lugar daquela que mais que qualquer outra pessoa the quer bem, compreende tudo e consegue ficar feliz.

No meu caso, com a argila, confeccionei um círculo com três palitos dentro e um fora. Falei um pouco da minha história, dizendo ter saído de casa muito jovem para estudar, aos 14 anos de idade. Por 16 anos aproximadamente não gozei da convivência familiar, sentindo-me sempre um de fora nas ocasiões em que ia a casa dos pais. Hoje, meus pais moram comigo; trazê-los para ficar ao meu lado significou acima de tudo o meu retorno à família perdida. Este foi o sentido do palito fora, sendo os três palitos dentro a representação de minha pessoa já reintegrada à relação com meu pai e minha mãe.

Foi surpreendente perceber o trabalho com o objeto concreto servindo de suporte para fazer eclodir os afetos, viabilizando inclusive a verbalização a respeito deles, e de uma maneira lúdica. Penso, por conta disso, ter entendido o real significado do que o professor tantas vezes falara em sala de aula: do brincar analítico. Esta é uma maneira de psicanalizar com leveza e descontração, 
favorecendo ao analisando colocar-se mais naturalmente e menos "encouraçado" que o habitual em suas sessões. 